\title{
Diània: rock polític, identitat i protesta al País Valencià
}

\author{
Diania: political rock, identity and protest in the Valencian country \\ Clemente Penalva-Verdú (Universitat d'Alacant, Alacant, Espanya) \\ Lluís Català-Oltra (Universitat d'Alacant, Alacant, Espanya)
}

Cita bibliográfica: Penalva, C. i Català L. (2021). Diània: rock polític, identitat i protesta al País Valencià. Disjuntiva, 2(2), 46-60. https://doi.org/10.14198/DISJUNTIVA2021.2.2.4

\begin{abstract}
Resum
Diània podria ser el nom d'una escena musical valenciana molt localitzada que val com a exemple del vincle entre la música popular i la vessant identitaria de l'acció política dels moviments socials. Aquest treball s'ha fet a partir d'una recollida de dades sobre aquesta intensa activitat artística musical (nombre de grups, estils, discografies, lletres i composicions i ubicació geogràfica) sobre diferents fonts de dades secundàries (mitjans socials, mitjans de comunicació digital). L'estudi troba, per una banda, la incidència de elements explicatius (culturals, històrics, socials i geogràfics) en la formació de l'escena. Per altra banda, l'anàlisi dels continguts de les composicions mostra com aquestes es mouen en un continu amb dos pols ben diferenciats (el grotesc i el solemne) que es corresponen amb dos instruments d'agitació política. Encara que connecten territori, identitat i protesta locals, els principals elements polítics estan associats amb les formes $\mathrm{i}$ reivindicacions actuals dels moviments socials globals.
\end{abstract}

\section{Paraules clau}

Rock Polític, música popular, Comarques Centrals Valencianes, identitat, moviments socials, glocalització

\begin{abstract}
Diània could be the name of a very localized Valencian music scene that serves as an example of the link between popular music and the identity aspect of the political action of social movements. This work has been done from a collection of data on this intense musical artistic activity (number of bands, styles, discographies, lyrics and compositions and geographical location) on different secondary data sources (social media, digital media ). The study reveals, on the one hand, the impact of explanatory elements (cultural, historical, social and geographical) on the formation of the scene. On the other hand, the analysis of the contents of the compositions shows how these ones move in a continuum with two well-differentiated poles (the grotesque and the solemn) that correspond to two instruments of political agitation. Although this scene has a stronge local character in terms of identity, protest and territory, its main political elements are associated with the current forms and demands of global social movements.
\end{abstract}

\section{Key words}

Political Rock, popular music, Valencian Central Counties, identity, social movements, glocalization 


\section{Introducció. La música popular i els moviments socials}

El rock és un fenomen cultural híbrid des de l'origen, efecte i vehicle de la globalització, i ha tingut la capacitat d'adaptarse a tots aquells llocs on s'ha estès per a produir fusions i transfusions que han provocat l'aparició de multitud de gèneres musicals híbrids. Aquests, a la vegada, i gràcies a la interconnexió tecnològica planetària, han pogut, en major o menor mesura, estendre's per a produir noves fusions, en un moviment constant, circular i sens fi. Com la cultura mateixa. La manera en què aquestes adaptacions locals s'han generat no deixa de ser un bon objecte d'estudi per a les ciències socials, que observen com interactua el pla cultural amb el social i també amb el polític. Precisament, aquesta vessant sociopolítica és la que més importa aquí. Partim del fet constatat que la música ha sigut un vehicle molt utilitzat i eficaç per a la transmissió no solament d'estils de vida, costums i mentalitats; sinó també de determinades idees i projectes polítics locals o globals. Per a entendre’ns clarament només hem de pensar en un tipus específic d’expressió musical que intenta condensar tot el conjunt abstracte de persones, símbols i idees que estimulen emocions i comportaments de significació política: l'himne. Siga oficial o no. Les revoltes populars contra la guerra del Vietnam, l’oposició a les dictadures, les lluites contra la dominació estrangera, els moviments d'alliberament nacional, etc., han comptat amb cançons populars que complien aquesta funció. Composicions musicals que són reproduïdes en contextos diferents per estimular la percepció de comunitat, orientar conductes o justificar la lluita política.

Només alguns temes i composicions populars esdevenen himnes, però moltíssimes creacions artístiques més comparteixen el paper de generadores d'emocions entre els seguidors de moviments socials, o s'inspiren en aquests moviments a l'hora de ser compostes. El "rock polític" (Pedelty and Weglarz, 2013) és una etiqueta per a designar aquesta faceta de la música popular, desenvolupada en la connexió que manté amb els moviments socials, per Eyerman i Jamison (1998), i a través de la qual es dóna notícia de grups clarament orientats a l'acció política o bandes, intèrprets i compositors anglosaxons amb un alt grau de compromís polític i de gran projecció internacional. Lestudi del rock polític pot abordar les nombroses bandes i autors escampats arreu que es vinculen a l'acció política en diferents espais sociopolítics del planeta. Espais o territoris en què la música expressa el fet nacional i el desplega dotant-lo de força simbòlica per adaptar-lo a un nou context de globalització (Biddle i Knights, 2007). Espais on la música és el camp simbòlic en què es representen les tensions polítiques i socials, com, per exemple, el conflicte entre el pop i el rock com a expressió de la pugna entre les diferents forces d’esquerra durant la transició espanyola a la democràcia (Mora i Viñuela, 2013).

Des d’aquesta perspectiva, aquest treball és una aproximació a la dimensió política de la música popular. Es porta a terme a partir de l'estudi de les manifestacions artístiques que es desenvolupen en un àmbit concret de la geografia valenciana, les Comarques Centrals, per un extens grup de bandes musicals que s'expressen en valencià. Trobem una forma d'expressió artística que conté, pel que fa a la música, les imatges i les lletres (en valencià), llocs quotidians, espais naturals, missatges polítics, símbols identitaris. Es tracta d'una activitat artística efervescent i molt densa d'una escena que es desenvolupa, principalment, en les gèneres musicals provinents del rock com són l'ska i el regae. Però que s'amplia al hardcore, punk, ritmes llatins, balkan folk, rap, trap, música electrònica, death metal, funk. Amb moltes cançons trufades de ritmes i instruments tradicionals autòctons (dolçaina, llaüt, bandúrria), es podria dir que la fusió musical i les al-lusions a l’àmbit local i a l’àmbit global, a l'ecologia, i amb crítica social, són molt comunes en una bona part de les composicions.

Per a fer aquest estudi es realitza una doble aproximació: a través del processament de dades estadístiques i a través de l'anàlisi textual de composicions musicals i continguts dels comptes dels mitjans socials (Facebook, Youtube i Bandcamp, principalment). Tot i que s'ha fet un important esforç de localització i registre d’artistes, d'audició de les obres, de visualització de vídeos i altres materials documentals, és tan vasta la producció que l'anàlisi no ha acabat de ser exhaustiva. De tota manera, creiem haver abastat els grups musicals de més difusió (Arthur Caravan, Aspencat, Auxili, La Gossa Sorda, Smoking Souls, Zoo) i una important representació dels menys coneguts. Ens serveixen per a presentar una sèrie de conclusions que aporten coneixement sobre la forma artística musical dels vincles entre política, identitat cultural i moviments socials, tenint en compte els respectius contextos històrics, geogràfics i polítics.

La música forma part d’aquesta vessant cultural, més específicament identitària, que l'estudi dels moviments socials porta incorporada. En els estudis sobre el comportament i l'organització dels moviments trobem enfocaments diferents. Mentre que les concepcions estructuralistes i racionals observen els moviments com una cosa que pren forma respecte de la manera eficient de mobilitzar i triar els propis de recursos (organitzatius, materials, culturals, humans, etc.), o com un procés en el qual es poden localitzar determinades oportunitats que ofereix el context polític (elits, aliances entre actors polítics, sistema institucional), en els últims temps es posa l’èmfasi en els factors culturals i constructivistes, que atribueixen més pes a les qüestions no racionals, com són la construcció de les identitats i les funcions de les emocions (Jaspers, 2012). 
Des d'aquesta perspectiva, l'art i, en concret la música, tenen un paper molt important en la generació d’emocions. Emocions que adquireixen una dimensió col-lectiva en les experiències de la música en directe. Cal assenyalar que, comparat amb altres expressions artístiques, la música és la que té un caràcter més participatiu. Com assenyala Frith (2003), l'experiència musical conté una situació concreta que és ritual i comunitària. A través de l’experiència i pràctiques musicals es connecta cos, sociabilitat i temps amb els relats culturals. Sociològicament, Durkheim explica bé el paper comunitari dels rituals seculars, que concep com un fet social amb funcions similars a les dels rituals religiosos: faciliten la cohesió i relliguen els membres de la comunitat. Òbviament, hi ha una gran quantitat de fenòmens de masses que poden cabre dins d'aquesta definició: assistència a un partit de futbol, manifestacions polítiques, i, com ja hem assenyalat, els espectacles artístics. No obstant això, al costat d’aquesta concepció local i estàtica del ritual tenim la dinàmica dels moviments socials i la relació que mantenen amb la música. La relació entre els moviments artístics i els sociopolítics s'observa en el fet que els moviments són font d’inspiració de les composicions musicals, però al mateix temps contribueixen a dotar de contingut aquests moviments. Com assenyalen Eyerman i Jamison (1998), els moviments socials són, a més de vehicles, contextos de canvi social. Els artistes activistes contribueixen al canvi perquè en la seua activitat artística proposen moltes vegades una cultura d'oposició a la cultura dominant. En sentit contrari, aprofiten aquesta concepció política alternativa com a font per a experimentar i innovar creativament, amb conseqüències destacades en la formació d’aquest component important de la creació artística que és l'autenticitat.

The dominant culture -the commercial, professional, or state, depending on the historical context- imposes the external standards, material conditions, and aesthetic criteria for artistic expression. The social movement, on the other hand, provides opportunities for artists to experiment and innovate and alter those standards and criteria, a context in which the artist can become a political as well as a cultural agent, and thus help shape an emergent cultural formation. (Eyerman i Jamison, 1998: 165).

Si a aquestes qüestions artístiques d’identificació grupal a través de les emocions hi afegim l'extensió d'un conjunt de creences (expressades en els relats culturals -que mencionava Frith- o en les narracions del lloc-) i la vinculació que estableixen amb els moviments socials, tenim el quadre gairebé complet de la dimensió política que volem abordar, i que transcendeix el concepte d'escena musical com a context particular de formació d'un determinat so musical. Encara que podríem assenyalar alguns elements comuns que ajuden a identificar la manera particular de fer música en aquest territori (la presència d'elements musicals tradicionals i l’efecte sonor d'interpretar les cançons en una llengua determinada), és tal la diversitat d'estils musicals derivats del rock, que preferim utilitzar el concepte de escena com a forma particular, localitzada espacialment, de portar la música al camp polític per part d’una “comunitat" d’artistes i públic. En els apartats següents tractarem el context geogràfic i cultural per a descriure-la i entendre’n millor el procés de formació.

\section{Diània o les Comarques Centrals Valencianes}

Ens van trobar, a l'inici d'aquesta investigació, amb un territori en el qual es desenvolupa aquesta activitat musical i que proporcionava la idea d'unitat cultural en un espai, amb unes especificitats geogràfiques i històriques comunes que poden incidir en la conformació d’unes pautes de creació artística. El nom identitari és Diània, apel-latiu que hem trobat en diferents manifestacions culturals en què la música està present: en els treballs de l’etnobotànic -amb incursions en la música com cantautor- Joan Pellicer, ${ }^{2}$ en un canal intercomarcal de TV (Diània TV) i en un dels festivals de música popular que travessen tot aquest territori: el festival Diània d'Ontinyent, un municipi pertanyent a aquest territori que intenta celebrar anualment, des del 2014, una trobada musical amb una important presència de bandes d'aquest espai geogràfic. Un festival que conjuga la música amb un desplegament cultural i cívic en activitats de tallers, art, esport autòcton (pilota valenciana) i taules redones sobre moviments socials, i que compta amb un important impuls autogestionat de base, com es pot veure en la organització de la segona edició el 2015. ${ }^{3}$ En els temes de les bandes Verdcel (“Ací"), de Lilit i Dionís (“Romanç de Neptú i Diània”) i, recentment, de Zoo ("Diània”) també apareix referenciada. Diània és, per tant, un significant que emergeix en el procés d’investigació i que considerem adequat per incloure tot un conjunt d’elements d'identificació grupal que en configuren el significat i que utilitzem aquí com a categoria analítica

2. Pellicer, Joan (2002). Meravelles de Diània: camins, paratges i paisatges de les comarques centrals valencianes. Picanya, Edicions del Bullent.

3. Assemblea Joves Meruts, Associació de Joves Socarells, Col-lectiu Cultural El Ganxo, Consell de la Joventut d'Ontinyent, Arran de la Safor, Ecoxarxa Séquia Mare, Muntis. 
per a delimitar espacialment l'objecte d'estudi. Significat, però, que potser no comparteixen tots els actors socials que produeixen el material sonor que és objecte d'aquest estudi ${ }^{4}$.

Considerem que la Diània o les també anomenades Comarques Centrals Valencianes (CCV) constitueixen un territori no reconegut administrativament dins de l'estructura territorial valenciana i espanyola, però amb prou ingredients per a ser-ho. Per començar, geogràficament, l'àrea que formen les comarques de l'Alcoià, el Comtat, la Marina Baixa, la Marina Alta, la Safor, la Vall d'Albaida i la Costera, amb ciutats de la importància de Benidorm, Alcoi o Gandia, configura una corona muntanyosa que es bolca a la mar i contrasta amb les planes hortolanes de València i del sud (des d'Alacant cap a Múrcia). De fet, s'hi situa al mig per exercir de baula i equilibri territorial entre els dos grans pols metropolitans (València i Alacant/Elx). Potser és aquesta orografia la que ha permès que la llengua catalana s'hi haja mantingut en nivells de coneixement i ús més elevats (Català i Penalva, 2018; Cens de població 2011, INE), i amb una menor interferència del castellà que a les zones planes (sempre ben comunicades amb la Meseta i el sud) i d'alta concentració urbana.

També té aquesta zona un passat històric com a entitat territorial, potser en part i inicialment, per aquesta configuració geogràfica. En temps preromans, el territori identificat actualment era en gran mesura el d'una gran tribu ibera, els contestans (que va donar nom al que avui és la capital del Comtat, Cocentaina). També l'organització musulmana en taifes (segle xi) va donar lloc a la de Daniya (amb capital a l'actual Dénia), amb límits semblants als que estem referint (Novell, 2015; 1997; Cervera, 2011: 61). Això va poder ser l'antecedent de la governació que institueix el rei Jaume I d’Aragó quan conquesta el Regne de València en el segle xiır. La subgovernació (després governació) Dellà del riu Xúquer, “de més enllà del riu Xúquer", tenia la capital a Xàtiva, una altra d’aquestes ciutats petites de les CCV, i s'assenta, gairebé amb la delimitació actual, com a pol d'equilibri territorial entre les dues grans ciutats del regne, València i Oriola, que eren massa lluny l'una de l'altra. Aquesta organització es va mantenir durant quatre segles i aquesta tradició va motivar que en el primer projecte de províncies (1822), durant el trienni liberal, hi haguera una província de Xàtiva, força similar a les CCV. El mapa provincial definitiu (1833), però, va reconèixer el poder que ja acumulava Alacant, per a repartir les CCV entre la seua província i la de València, i relegar-les a una referència romàntica o identitària (Català, 2012: 131-132; vegeu també Novell, 2015; Membrado, 2013: 8-12; Cervera, 2011: 61-62; Membrado, 1997: 19; Sanchis, 1976: 41-44).

Avui dia, les Comarques Centrals Valencianes són, efectivament, un projecte identitari, en part lligat a alguns postulats del nacionalisme perifèric valencià, però també és una realitat socioeconòmica que ha aflorat a partir de diferents estudis (Català, 2016: 17-18), tant des de l'economia, com des de la geografia humana (vegeu, només com a mostra, Casado i Salom, 2007; i Salom i Albertos, 2014). És un espai d’especialització industrial (interior) i turística (costa), amb dinàmiques de competència col-laborativa i de gran capacitat adaptativa (Ybarra, 2011; Català, 2016: 11). Hi ha mobilitat laboral, acadèmica i d’oci al llarg i ample de les CCV, sobre la base d'aquesta xarxa de ciutats petites o intermèdies (25.000 a 75.000 habitants), no únicament a la costa, sinó també a l'interior, que, llevat d’una zona central més muntanyosa de pobles menuts, té una densitat acceptable per la franja que acompanya l'eix industrial de l'autovia A-7 (Novell, 2015). Per tant, és una zona policèntrica, internament harmònica i que dóna equilibri a tota l’àrea extensa de València; que té un gran desenvolupament de la societat civil, i més encara en la vessant cultural lligada a la llengua i altres manifestacions que caracteritzen aquesta zona singular tan decisiva en la definició de la valencianitat (Català, 2012).

La localització geogràfica d’aquestes agrupacions artístiques queda reflectida en la taula següent. Una bona part està elaborada a partir de dades extretes el 2018 del portal Viasona ${ }^{5}$ sobre grups que han produït i difós obres musicals i que canten en català. Aquesta taula mostra l’enorme concentració de bandes, atenent la localització i el nombre, i la densitat poblacional com a base de comparació entre municipis i comarques. Sobre un conjunt molt nombrós d’entitats locals (el factor localista es tractarà més endavant), destaca, en primer lloc, la gran presència de bandes de rock que canten en valencià ( 167 bandes localitzades en la base de dades que procedeixen de 35 municipis), i, d'altra banda, l'alta concentració en dues zones separades per una franja central. Aquestes dues zones caracteritzen dues subescenes, una

4. Diània és tracta d'un objecte d'estudi que està "en construcció" perquè cal fer constar algunes limitacions que assumeix aquest treball. La principal és que hem accedit a aquestes pràctiques culturals i polítiques de manera indirecta, a través de les gravacions musicals i dels continguts mediàtics (premsa i xarxes socials). No hem interactuat amb els participants (artistes, públics, intermediaris) d'aquesta escena mitjançant entrevistes o dinàmiques de grup, per a accedir, en el cas dels artistes, a la manera en què perceben i construeixen la seua vinculació amb l’obra i el procés creatiu, i com la connecten amb l'activisme i el compromís polítics. Pel costat de l'audiència, tampoc hem accedit al context de recepció -i al procés de descodificació-, ni al sentit que donen els públics a l’experiència musical, així com a la seua militància i participació política.

5. https://www.viasona.cat/ 
més prop del litoral amb una economia de base agrària, però que en l'actualitat es caracteritza pel monocultiu turístic residencial; i una segona, també de base agrària, però amb un destacable desenvolupament industrial des de fa vora dos segles. S’observa com una sèrie de petites localitats (Agres, Alfafara, Castellonet de la Conquesta, Pego, Sella) mostren una densitat de més de 10 bandes per cada 10.000 habitants. En aquest sentit, al marge de les excepcions de petits pobles de l'interior despoblat, la segona línia litoral, amb municipis de 1.000 a 10.000 habitants, i l'eix interior industrial de l'autovia A-7, són les zones de més densitat de bandes. Amb una producció de més de 400 discos, aquesta escena musical resulta enormement prolífica, amb una mitjana de 2,5 discos per banda, molts dels quals autoproduïts.

Taula 1. Nombre de grups a les Comarques Centrals del País Valencià que canten en valencià segons població (2018)

\begin{tabular}{|c|c|c|c|c|c|c|c|c|c|}
\hline Comarca & Municipi & Grups & $\begin{array}{l}\text { Habs. } \\
\text { (2018) }\end{array}$ & $\begin{array}{c}\text { Ngrups } \mathrm{x} \\
10.000 \mathrm{hbs}\end{array}$ & Comarca & Municipi & Grups & $\begin{array}{l}\text { Habs. } \\
(2018)\end{array}$ & $\begin{array}{c}\text { N grups } x \\
10.000 \text { hbs }\end{array}$ \\
\hline \multirow{6}{*}{ L'ALCOIÀ } & Alcoi & 20 & 59.354 & 3,4 & \multirow{11}{*}{$\begin{array}{c}\text { LA } \\
\text { MARINA } \\
\text { ALTA }\end{array}$} & Benissa & 8 & 11.288 & 7,1 \\
\hline & Onil & 3 & 10.461 & 2,9 & & Calp & 1 & 23.326 & 0,4 \\
\hline & Castalla & 3 & 7.600 & 3,9 & & Dénia & 4 & 42.827 & 0,9 \\
\hline & Banyeres & 1 & 7.090 & 1,4 & & Ondara & 1 & 7.076 & 1,4 \\
\hline & Total comarca & 28 & 110.104 & 2,5 & & Pedreguer & 3 & 7.881 & 3,8 \\
\hline & & & & & & Gata de Gorgos & 2 & 6.243 & 3,2 \\
\hline \multirow{5}{*}{$\begin{array}{c}\text { EL } \\
\text { COMTAT }\end{array}$} & Agres & 1 & 561 & 17,8 & & Pego & 15 & 10.133 & 14,8 \\
\hline & Cocentaina & 7 & 11.520 & 6,1 & & Xàbia & 5 & 28.016 & 1,8 \\
\hline & Alfafara & 1 & 406 & 24,6 & & Xaló & 1 & 2.868 & 3,5 \\
\hline & Muro D'Alcoi & 1 & 9.315 & 1,1 & & Total comarca & 40 & 178.203 & 2,2 \\
\hline & Total Comarca & 10 & 28.047 & 17,8 & & & & & \\
\hline \multirow{4}{*}{$\begin{array}{c}\text { LA } \\
\text { COSTERA }\end{array}$} & Canals & 1 & 13.516 & 0,7 & \multirow{6}{*}{$\begin{array}{c}\text { LA } \\
\text { MARINA } \\
\text { BAIXA }\end{array}$} & Altea & 1 & 22.558 & 0,4 \\
\hline & Xàtiva & 7 & 29.623 & 2,4 & & Benidorm & 2 & 70.450 & 0,3 \\
\hline & Total comarca & 8 & 71.830 & 1,1 & & Callosa d'Ensarrià & 3 & 7.522 & 4,0 \\
\hline & & & & & & Sella & 2 & 577 & 34,7 \\
\hline \multirow{9}{*}{$\begin{array}{c}\text { LA } \\
\text { SAFOR }\end{array}$} & $\begin{array}{l}\text { Castellonet de la } \\
\text { Conquesta }\end{array}$ & 2 & 141 & 141,8 & & La Vila Joiosa & 2 & 35.199 & 0,6 \\
\hline & $\begin{array}{l}\text { Benifairó de la } \\
\text { Valldigna }\end{array}$ & 1 & 1.558 & 6,4 & & Total comarca & 10 & 190.968 & 0,5 \\
\hline & $\begin{array}{l}\text { Tavernes de la } \\
\text { Valldigna }\end{array}$ & 6 & 17.254 & 3,5 & \multirow{7}{*}{$\begin{array}{c}\text { LA } \\
\text { VALL } \\
\text { D'ALBAIDA }\end{array}$} & Agullent & 1 & 2.388 & 4,2 \\
\hline & Gandia & 15 & 75.798 & 2,0 & & Bocairent & 2 & 4.142 & 4,8 \\
\hline & Bellreguard & 3 & 4.618 & 6,5 & & Albaida & 5 & 5.914 & 8,5 \\
\hline & Oliva & 5 & 25.224 & 2,0 & & Castelló de Rugat & 2 & 2.298 & 8,7 \\
\hline & La Font d'En Carròs & 3 & 3.778 & 7,9 & & Ontinyent & 11 & 35.761 & 3,1 \\
\hline & Villalonga de la Safor & 1 & 4.370 & 2,3 & & Total comarca & 21 & 87.555 & 2,4 \\
\hline & Total comarca & 36 & 174.129 & 2,1 & & & & & \\
\hline
\end{tabular}


En aquest context històric i geogràfic es desenvolupa una escena musical que és l'objecte d'estudi d'aquest treball. Una escena multilocal, en la qual els grups es formen amb músics d'una localitat o amb músics de municipis veïns, i una escena en què les formacions musicals troben múltiples espais laborals, professionals, culturals i artístics a partir del conjunt d'activitats culturals (festives i artístiques) que s'hi desenvolupen durant tot l'any.

Les referències al marc local són molt freqüents en les lletres de les cançons: ${ }^{6}$ topònims lligats a llocs on es realitzen diferents activitats de la vida quotidiana, i cançons que remeten a pobles i ciutats, gastronomia, construccions, paisatges i camins, aquells que precisament reflecteixen la mobilitat intercomarcal i la idea d'unitat territorial. Trobem recorreguts entre poblacions (com la tradicional "Malaguenya de Barxeta" que recupera, entre d'altres, Pep Botifarra, i "Xixona" de Mugroman) o recorreguts entre paratges. En "Ponts", d’Els Ullals, s'assenyala la interacció entre activitat humana i la natura en els llocs que va travessant el riu Xúquer. Hem de dir que l'afecció al municipi d’origen està potenciada per la idiosincràsia localista del País Valencià (reflectida en les enquestes sobre identificació territorial) i que alguns han vist com a símptoma de rebuig a la identitat valenciana, però també com a aposta pel món local, potser com a element vertebrador construït des de baix, que pot plantejar resistència a la cultura global (Català, 2012, citant Llopis i Vidal, 2006). Les referències locals són la base d’identificacions amb pobles i territoris més amplis. Aquesta idea de comunitat, país, nació, es fonamenta en l'afecte a cadascuna de les parts que comparteixen una història i llengua comunes. Com a mostra, un grup dèxit notable (fora, fins i tot, dels límits del País Valencià, i que ha arribat a fer gires internacionals) com és La Gossa Sorda va concloure la seua activitat com a formació musical amb una sèrie de concerts de comiat, l'últim dels quals (recordem el significat social del ritual que constitueix la música en directe) es va celebrar a la seua localitat d'origen, Pego.

\section{La música al País Valencià}

No es pot abordar aquesta escena musical sense al-ludir al context musical de formació. La música popular al País Valencià ha estat molt vinculada històricament a l'entorn local. Les cançons tradicionals han estat lligades a l'espai més pròxim; i la particularitat en aquest territori ha sigut la presència de la música per a acompanyar tota mena de festes populars. La festa, com a principal manifestació cultural, no solament per dedicació i activitat comunitària popular, sinó també per rellevància econòmica, arriba a ser, en aquest territori, el principal element de vertebració social i cívica. Aquest gran desplegament festiu fa que siga molt difícil trobar un municipi en què no hi haja agrupacions musicals. L'informe de la Federació de Societats Musicals de la Comunitat Valenciana (FSMCV, 2015) dóna una dada molt significativa d'aquest vessant musical que s'articula en la societat valenciana localitat a localitat: el $90 \%$ dels municipis valencians tenen societat musical. En xifres absolutes, l'FSMCV ha censat un total de 1.686 formacions artístiques en el si de les societats musicals. Desglossades amb més detall, apareixen 1.075 bandes, 174 orquestres, 233 cors, 133 grups de cambra, 52 big bands i 19 grups de tabal i dolçaina. La mateixa federació agrupa 547 societats musicals del total, amb 40.000 músics, 60.000 alumnes d’escoles de música i 200.000 socis. El mateix informe (FSMCV, 2015) indica que gairebé el $50 \%$ de totes les societats musicals d'Espanya estan radicades al País Valencià. ${ }^{?}$

Aquestes societats musicals s'ocupen de la formació musical d’una gran quantitat de població. En algunes formacions de rock que estem estudiant, la banda musical local -juntament amb els instituts d'ensenyament mitjà- ha estat el germen de la seua activitat. El vent, essencial en l'ska, la presència de la dolçaina i la d'instruments de corda tradicionals han permès aquesta fusió de tradició i modernitat que ha generat un so propi, present en un gran nombre de temes musicals dels gèneres derivats del rock que estem considerant en aquest treball. Les escoles de música d'aquestes societats (com ara conservatoris elementals) i els mateixos conservatoris -centres especialitzats en la formació professional musicalno són llocs estranys per a molts dels integrants d'aquests grups estudiats. En algunes narracions, extretes de la feina documental a les xarxes socials, sobre com estan formats els grups, trobem aquests elements institucionals. Els grups de rock els formen en bona part individus que treballen semiprofessionalment en l'àmbit de la música. Compaginen l'activitat en aquests grups amb la participació en activitats poc regulades com són les que desenvolupen les orquestres municipals, bandes de música o xarangues que acompanyen cada agrupació festera (de filades, comparses, penyes,

6. Com a exemples, el vídeo de "Vents» d’Arthur Caravan, gravat en el paratge de la Font Roja, a Alcoi. Eldemuro és un raper que fa del seu lloc de procedència (Muro d’Alcoi) el seu nom artístic. En les lletres de "Cap per avall» del grup Zoo i en "Farem saó» de La Gossa Sorda es fonen llocs, activitats i memòria.

7. http://www.ateneulavila.com/contingut/docs/FSMCV_Censo\%20agrup_artst.pdf 
colles, falles, segons es denominen les fraccions de les diferents festes) en passacarrers o desfilades al llarg de la geografia valenciana. En alguns casos, les dues activitats permeten, en certa manera, viure de la música. El rock és una manera de provar altres estils, altres formes d'expressió artística que consideren més creatives i personals, enfront de la reproducció del repertori de temes més o menys comuns dels esdeveniments festius. És una de les formes d'arribar al rock. Una altra és que, a partir d'una base musical molt limitada, grups d'amics amb poca formació musical s'ajunten per a formar una banda de rock; i en el procés d'aprenentatge dels instruments bàsics d'aquest gènere (guitarra, baix i bateria) van incrementant el desenvolupament i la complexitat musicals, amb la incorporació d'instruments de vent que toquen nous membres procedent d'aquestes bandes musicals tradicionals. D’altra banda, es forma un circuit d'actuacions localitzat principalment en aquest espai geogràfic multilocal, que s’amplia a altres comarques del País Valencià i a altres territoris de parla catalana, i que tenen a la capital de la comunitat autònoma, València i, de vegades, a Barcelona les plataformes per a ampliar-ne la popularitat.

En termes d'indústria musical, en aquesta escena preval l'autoproducció (enregistraments realitzats pels mateixos grups en estudis de gravació casolans) i l’autogestió (en inversió, enregistrament en estudis, promoció -a través dels mitjans socials-, drets d'autor, programació i negociació de concerts i, fins i tot, la producció artística paral-lela relativa a la fotografia o el vídeo). No obstant això, quan els grups arriben a cert nivell de popularitat poden delegar part o totes aquestes tasques en altri. En aquest moment, les productores, els estudis de gravació o el management comencen a realitzar el seu paper, moltes vegades en empreses que aglutinen totes aquestes tasques assenyalades anteriorment. No és exclusiu d'aquesta escena. En un sector -el musical- en què l'oferta és molt més gran que la demanda i aquesta es consumeix principalment a partir de descàrregues gratuïtes d'Internet, no hi ha més font d'ingressos que les actuacions en directe. El resultat és un sector molt precaritzat en el qual és molt difícil dedicar-se professionalment a totes aquestes tasques de producció i promoció. Davant l'absència, durant molts anys, d'una política cultural que fomentara aquesta activitat musical, l'emergència i desenvolupament d'aquestes bandes ha estat possible, en part, pel suport de certes associacions cíviques de defensa del valencià, i pels nivells més propers de l’administració pública, els ajuntaments. Així, a més dels espais de participació autogestionada (els ateneus, casals populars i els centres socials autogestionats són llocs molt visitats per les bandes), han sigut els festivals (la Gira itinerant d'Escola Valenciana, el Tirant lo Rock de l'Associació Cultural del País Valencià) i concursos (Premis Ovidi Montllor del Col-lectiu Ovidi Montllor d'artistes valencians i certàmens d'actuacions i lletres en valencià d'alguns ajuntaments) els espais artístics on aquesta escena s'ha difós. Espais molt reduïts de difusió en comparació amb els grans festivals que acullen en el mateix territori formacions estrangeres i grups de més difusió comercial (els coneguts internacionalment FIB, Arenal Sound, Rototom, Low Festival, Medusa). Com indiquen els mateixos artistes, aquesta autogestió els ha permès un grau més elevat de llibertat creativa i una actitud de resistència cultural ${ }^{8}$ que constitueixen, juntament amb l'expressió "natural" en la llengua materna (enfront de la impostura de cantar en anglès, i en alguns casos, en castellà), el compromís polític i l'actualització de la tradició musical, la seua principal font d’autenticitat artística. Si hi afegim la pràctica musical preferida i obligada -els discos ja no són el suport econòmic- de les actuacions en directe, es conforma globalment -en aquesta escenal'estructura completa d'aquest concepte multisèmic -l'autenticitat- bastit socialment i determinat culturalment sobre els pols d'expressió artística:

Les fonts d'autenticitat musical a Diània com a hipòtesi

\begin{tabular}{|c|c|}
\hline Naturalitat & Artificialitat \\
\hline Llengua materna & Altres llengües \\
\hline Implicació política & Neutralitat ideològica \\
\hline Independència creativa & Direcció artística \\
\hline Resistència cultural & Hegemonia cultural \\
\hline Actuacions en viu & Gravació en estudi \\
\hline
\end{tabular}

8. En una entrevista a la banda Aspencat, a "El Periódico" en boca de Kiko Tur "Hay toda una generación de grupos que hemos crecido empujando el muro construido por el PP contra nuestra cultura. Como había tanta hostilidad, nos hemos acostumbrado a ser autogestión y auto-todo", argumenta, subrayando que "los grupos valencianos llevan esa resistencia incorporada en su ADN" https://www.elperiodico.com/es/ocio-y-cultura/20171020/entrevista-aspencatrazzmatazz-curtcircuit-6368041 
Per a aquesta escena s'articula territorialment un circuit d'actuacions en el qual hi ha menys presència de sales que de festivals. Escampats per tot el País Valencià (i per altres localitats dels territoris de llengua catalana), esmentem uns quants festivals que recorren tot el territori de les Comarques Centrals: Diània (Ontinyent), Festivern (Tavernes de la Valldigna), Fesporrat (Altea), Figatell Sound (Oliva), Espiga Rock (Sueca), FIGA(Festivalet Independent de Gata), Poma Rock (Agres), Pirata Rock (Gandia), Festival Mil (Xàtiva).

Continuant amb aquest context musical valencià, aquesta escena, que es desenvolupa a partir de la segona meitat dels anys noranta, es nodreix de diferents fonts estilístiques, tant regionals com internacionals, com es pot veure en l'obra de Frechina (2011) La cançò en valencià. Dels repertoris tradicionals als gèneres moderns. En primer lloc cal esmentar com a font la Nova Cançó, moviment musical català, valencià i balear que va començar els anys seixanta de segle passat i que va orignar la primera modernització de la música tradicional valenciana, i les primeres fusions. Tenen com a referència cantautors valencians com Ovidi Montllor, Raimon, o conjunts com Al Tall, que influeixen musicalment, però també en el pla polític, en el seu esforç per difondre la cultura valenciana a través de la música cantada en valencià. Algunes de les interpretacions d’aquestes formacions objecte d’estudi són versions de cançons d'aquests grups històrics, sobretot les de més capacitat simbòlica per a representar aquesta unió entre política i cultura: "El cant dels maulets" o "Tio Canya” (Al Tall) com a exemples. En segon lloc, tenen com a referència un nou impuls a mitjan anys noranta, d'on procedeix i es reconeix la major influència en l'activitat creativa: la banda Obrint Pas, que incorpora la dolçaina a composicions punk i reggae -amb el Rock Radical Basc (Espinosa i López, 1993; Mosso, 2013) com a principal influència musical i política-, i que més endavant incorporarà ritmes llatins i l'ska. En les seues lletres hi ha un component polític molt accentuat, amb crítica social i solidaritat amb els pobles del sud, al mateix temps que es reivindica la independència dels Països Catalans. El seu internacionalisme es veu reflectit en la col-laboració amb artistes de fora de l'estat espanyol i en una sèrie de concerts arreu d'Europa, que denominen gira internacionalista. L'empremta que Obrint Pas ha deixat en grups de gran èxit a les comarques centrals com La Gossa Sorda i Aspencat és evident, i s'erigeix com a precedent tant en la forma musical com en les lletres. Són grups que, al seu torn, han esdevingut referència i inspiració per a moltes de les bandes d’aquesta escena.

Val a dir que alguns estils resultants d'aquestes fusions expressen una forma local d’expressió musical universal. El rap en valencià ofereix un tipus particular de sonoritat i aprofita la gran abundància en el seu vocabulari de mots monosil-làbics i bisil-làbics que fan més fàcil la composició de les cançons. A més, la improvisació del rap connecta amb cants tradicionals com el cant d'estil, en què el o la cantant imposa la seua forma particular d'executar els ornaments d'un cant lliure, sobre uns esquemes melòdics prefixats, amb l'ajuda del versador, el paper del qual és dir a cau d'orella l'estrofa, un text improvisat que parla de la pròpia situació i dels personatges i públic presents en l'actuació, incloent-hi el públic. En alguns casos es produeixen desafiaments entre els cantadors o les cantadores a la manera de les baralles de galls del hip-hop actual, que a voltes provoquen les rialles del públic. Frechina hi afegeix la dimensió comunitària quan apunta la figura del versador com a:

[...] portaveu de la comunitat: en consolida o subverteix els valors, en transmet la ideologia, denuncia greuges, reclama drets, afalaga els amics i vitupera els enemics, contribuint notòriament a la restauració simbòlica dels vincles comunitaris (Frechina, 2012, 71)

\section{El context global de protesta política}

Una vegada contextualitzat territorialment i culturalment aquest espai artístic, podem abordar-ne directament la faceta sociopolítica. Per a fer-ho hem de referir-nos al clima polític que envolta la formació d’aquesta escena musical. En un marc més ampli, tot l'estat, Del Vall i Fouce (2016) realitzen aquesta contextualització política per a veure’n la influència en l'àmbit del rock independent a Espanya. És possible que la formació d'aquesta escena musical valenciana no s'entenga si no es té en compte el cicle de mobilitzacions populars que comença a mitjan anys noranta, les quals tenen un marcat caràcter internacional i una nova expressió al sud d’Europa, i a Espanya, en concret, amb les mobilitzacions multitudinàries i esteses arreu de l'Estat el 15M de 2011. Es tracta de mobilitzacions de protesta que denuncien moltes coses alhora: precarietat econòmica, corrupció política, desigualtat social, desconfiança amb la política partidista, i, fins i tot, cap al mateix sistema capitalista. La crisi política té com a principal causa la crisi econòmica que, a Espanya, va comportar una caiguda abrupta des del període més important d’expansió del consum a la depressió econòmica -també internacional- que encara es continua patint en forma d'austeritat del sector públic i d'increment de la pobresa i la desigualtat (Alaminos i Penalva, 2016).

El 15M espanyol es pot inserir en un cicle de protestes global (Raffini, Penalva, Alaminos, 2015) que comença a mitjan anys noranta (moviment altermundialista amb l'aixecament de l'EZLN a Chiapas) i que no es pot dir que 
s'haja tancat. En aquest interval temporal trobem un conjunt de fites de mobilització global en què la generació de músics que estudiem s'ha socialitzat políticament. Les mobilitzacions arranquen al principi dels anys noranta amb les reivindicacions d'ajuda al desenvolupament (la campanya del 0,7 \%), seguida per les protagonitzades pels moviments antiglobalització (mitjan anys noranta) i per les protestes contra la guerra de l'Iraq, per acabar amb el 15M (que enllaça amb les primaveres àrabs i els moviments de protesta en molts altres països: Estats Units, Regne Unit, Brasil, Xile, entre d'altres, i la convocatòria mundial del $15-\mathrm{O}$ del mateix any). En l'àmbit valencià, l'anomenada Primavera Valenciana (febrer de 2012) va suposar l'episodi de protesta més sonat per la repressió policial i les protestes que se’n derivaren, així com per les detencions que hi va haver. En el mateix àmbit urbà, Salvem el Botànic, Salvem el Cabanyal i les protestes contra els megaprojectes del govern conservador del PP a València són antecedents clars, en les quals es planteja la defensa del patrimoni cultural i de la cultura valenciana (Albert i Hernández i Martí, 2011).

Una altra fita, aquest en l’àmbit comunicatiu, serien les protestes contra el tancament de la Ràdio Televisió Valenciana el 2013. La via pública de difusió de la llengua i cultura pròpies es tancava definitivament després d’anys de pèssima gestió i de caiguda d'audiència. Les lluites tenien un marcat caràcter reivindicatiu cultural davant la penosa política del PP, orientada a l'execució de grans obres i projectes mediàtics per tal de connectar internacionalment la ciutat de València, i que va originar un gran malbaratament de diners públics i l'extensió de la corrupció. En l'àmbit rural, amb menys repercussió, invisibilitzat enfront de les grans mobilitzacions urbanes, tenim la lluita multicultural (important presència de residents estrangers de la UE) contra la Llei urbanística del govern valencià, que era un altre exemple de la "idea" de "defensa" del patrimoni cultural i mediambiental d’aquest govern, supeditat a l'expansió immobiliària.

No es pot desconnectar aquesta visió identitària de la política i les formes de participació política no convencional amb l'esquerranisme. Des de la transició i a partir de l'obra de Joan Fuster (1962), les formacions d'esquerra entenen que els territoris que comparteixen l'ús històric del català formen una realitat cultural, que fins i tot pot tenir sentit polític. Enfront de la transversalitat social de la defensa de la llengua a Catalunya, on la burgesia urbana ha conservat i defensat l'ús social de la llengua, al País Valencià l'idioma s'ha conservat més aïna per l'ús de les classes populars localitzades en l'àmbit rural, ja que des de finals de segle XIx les burgesies instal-lades a les grans ciutats van anar abandonant aquesta llengua perquè consideraven el castellà com a llengua culta, element simbòlic de distinció enfront del valencià de les classes populars. Aquest fet ha implicat, juntament amb l'arribada de població de parla castellana, que el valencià tinga una presència molt reduïda a les grans ciutats, on, per imitació social d'aquestes pràctiques, el valencià no ha sigut transmès de pares a fills, ni per part de les famílies valencianoparlants originàries de les ciutats, ni per les que hi van migrar producte d'una mobilitat interna del camp a la ciutat (Montoya, 2012).

Aquests processos han derivat en la defensa i la promoció de l'ús social del valencià per part de l'esquerra en dues vessants complementàries: normalitzar-ne l'ús (per a tots els àmbits, no reservat únicament al familiar o com a element folklòric festiu) i incorporar-lo a l’educació per assegurar-ne no tan sols el coneixement i ús, sinó també la dignificació com un dels elements culturals valencians més representatius. El sistema educatiu valencià, des de principis dels anys vuitanta del segle passat, ha inclòs la possibilitat que el valencià esdevinga llengua vehicular, i que el coneixement de la llengua estiga incorporat en tots els programes d'estudi, fins i tot per a famílies que opten pel castellà com a llengua vehicular. I això, amb més o menys impuls, s'ha mantingut en totes les polítiques educatives, sense importar el signe polític del partit governant.

No obstant això, més enllà de la incorporació al sistema educatiu, la perspectiva de l'esquerra valenciana és que l'impuls del valencià ha de ser més actiu en la seua promoció cultural. Els governs de el Partit Popular no ho han dut a terme en els seus vint anys de govern (1995-2015). Aquesta és una de les pugnes més evidents que travessen culturalment i políticament al País Valencià i que es manifesta en la constant caracterització diferencial dels símbols identitaris: el nom de la llengua, el nom del territori, la bandera, l'himne. Dos universos simbòlics en pugna constant que és el correlat, en definitiva, de narratives ben diferenciades que associen la identificació del que és valencià amb referents catalans o espanyols.

Per a l'esquerra, la dissolució dels elements valencians dins de la cultura hegemònica com a element regional que contribueix al patrimoni cultural espanyol no és més que una estratègia de la dreta per a negar el caràcter diferencial de la cultura valenciana i col-locar-la en un pla subordinat, únicament folklòric. O més encara, una manera de desqualificar totes les polítiques i iniciatives de l'esquerra valenciana, i una manera d'autopresentar-se les forces polítiques de dreta com a autèntiques valencianes. Realment, l'esforç més important de recuperació i estudi de les tradicions i formes de viure valencianes l'ha realitzat el projecte cultural de l'esquerra, que històricament ha vinculat aquest treball identitari amb les lluites socials orientades a la igualtat social, l'increment de les llibertats i la promoció de les classes populars. Esforç continuat que va tenir el primer gran impuls en les dècades dels anys seixanta i setanta de segle xx quan, precisament, assistim a la modernització de la música tradicional valenciana amb conjunts musicals com Al Tall i cantautors com Raimon i Ovidi Montllor. En paral-lel apareixen els treballs de referents intel-lectuals que intenten 
ressituar la cultura valenciana en el context històric dels territoris de parla catalana, amb Joan Fuster com a figura destacada. Cal indicar que no es tracta d'una qüestió específica valenciana. Aquesta recuperació de la tradició i la seua modernització es va produir de la mateixa manera en tots els territoris de l'estat espanyol (Galícia, Catalunya, Euskal Herria, Aragó, Castella) i es correspon amb l'extensió del folk en l’àmbit internacional, com a símptoma de recuperació -també en l'àmbit acadèmic- de les tradicions orals.

\section{Els continguts de la Diània musical: entre la sàtira i la solemnitat}

Fins a aquest punt hem traçat una caracterització general de les temàtiques i estils d'aquesta escena musical, emfatitzantne el caràcter local, identitari, anticapitalista i internacionalista. Si en apartats anteriors al-ludíem a les influències o, fins i tot, als factors estructurals i conjunturals que expliquen l'emergència d'aquest fenomen cultural, ara podem fer el camí contrari. Es pot fer una revisió de tots els símbols de la identitat valenciana en els continguts videogràfics, sonors i lírics que ha produït aquesta escena, i que és útil per a observar com aquest fenomen artístic contribueix a reconstruir un imaginari col-lectiu valencià d’orientació política. Centrant-nos en l'estil i el contingut, podem veure l'activitat artística com a performativa. Entesa com a discurs, la música provoca no tan sols emocions i significats (Alaminos Fernández, 2014) que contribueixen a la conformació d’una visió de món, sinó també a un conjunt de comportaments. En aquest sentit, en termes de contingut, representant la identitat a partir d'un conjunt saturat de símbols (llocs, gastronomia, festa, història), la música la reprodueix i l'àmplia, de manera que esdevé un element identitari més. En termes de composició artística, a més, prefigura determinades maneres de dur a terme l'acció política.

Observem que les lletres de les cançons es mouen en un continu amb dos pols ben diferenciats, que van del grotesc i al solemne. Això ens duu a proposar, com a hipòtesi, una manera de classificar aquestes manifestacions artístiques en aquestes dues categories. Cal advertir que, encara que apareixen elements característics en bona part dels temes musicals de gairebé tots els grups i artistes analitzats, no hi ha cap banda o compositor que represente un tipus o un altre de manera "pura". Tenim, d’una banda, que la paròdia, l'exageració, la ironia, l'equívoc, la sornegueria o l'element escatològic són molt presents en les manifestacions culturals valencianes (fins i tot se’ls reconeix com a estereotip en la personalitat dels valencians) i que connecten directament amb la dimensió carnavalesca de la festa present en els participants (vestir-se de moro o cristià, hortolà o hortolana, faller o fallera és una manera de participar en qualsevol festa valenciana) i en altres elements escènics (els missatges satírics de les falles i les fogueres, o els contranbados dels moros i cristians). D’altra banda, en un to més seriós, s'expressen greuges, denúncies, lluites i derrotes, situacions d'injustícia, memòria de l’oprobi. L’efecte emotiu buscat no és l’alegria -i la seua manifestació biològica externa, el riure-, sinó la indignació, la ràbia. En tots dos pols s'expressa clarament el mateix posicionament polític, encara que la forma d’expressió siga clarament diferenciada al voltant d'aquests instruments d'agitació, que podríem categoritzar com a xirigota (sàtira) o himne (solemne) polítics. Si l'himne utilitza elements simbòlics del passat, com a ancoratge idealitzat d'un programa polític present o orientat cap al futur; la paròdia s'incrusta en l'etern present.

Com a exemples del caràcter satíric, podem assenyalar: Lilit i Dionís ${ }^{9}$, Bacora, Ix! -producte de la intensa activitat artística de Pau Miquel Soler- o Toni de l'Hostal. Deixant al marge els sainets i altres gèneres teatrals que, com reconeixia el mateix Fuster (Planas, 2012), van permetre conservar la llengua valenciana durant el segle XIX, aquest estil formaria part d'una tradició de la cançó popular moderna valenciana que connecta directament amb el grup Els Pavesos, del cantant i actor Joan Monleón en els anys setanta. En el gènere cantautor connectaria amb el també cantant i actor Ovidi Montllor i, passant a la generació següent de la música cantada en valencià dels anys noranta, amb la banda Bajoqueta Rock. ${ }^{10}$

A l'altre pol, l'himne és un exemple clar de transmissió d’emocions per orientar l'acció política a partir de la música. Es tracta d'un ús intensiu de significants relatius a esdeveniments històrics: la batalla d’Almansa i la destrucció de Xàtiva durant la guerra de Successió a principis de segle XviII, els herois militars d’aquest conflicte, les víctimes d'atemptats

9. En aquest video https://www.youtube.com/watch?v=p_kk3EdGOD0, sobre el tema “El ball del Jaguar”, Lilit i Dionís va traslladant llocs i elements geològics americans al paisatge autòcton (rius i pobles de la comarca) per a formar un collage molt peculiar d'elements simbòlics de diferents cultures. Amb un to humorístic (ja el títol "El ball del jaguar» juga amb la similitud fonètica entre el jaguar -animal americà deïficat en la mitologia d’Amèrica Central- i el paratge de la vall de Laguar de la Marina Alta) que val per a de fer parangó de les lluites de resistència cultural i ecològica de qualsevol lloc del món.

10. En la vessant humorística, paròdica i escatològica, connecten també amb altres conjunts valencians que cantaven en castellà, com el grup dèxit Inhumanos i el menys conegut Gigatrón, els quals, al final dels noranta, parodiaven el heavy metal. 
feixistes d’ençà de la transició, la repressió contra les llibertats, els personatges referents de la teoria i acció política socialista i anarquista, la Guerra Civil i, internacionalment, líders dels moviments socials llatinoamericans. També hi ha al-lusions a l'efecte del neoliberalisme en la pobresa, a la precarietat laboral, a la repressió policial. Aquesta categoria analítica forma l'estil preponderant, i Aspencat i el seu tema "Música naix de la ràbia" nés paradigmàtic.

Música naix de la ràbia / Sona la freqüència per fugir d’aquesta gàbia / Som com un as en la baralla / Som com el dimoni que camina entre la flama / Soterre les penes, jo sé que avance a base de contradiccions, / a mi em mouen les passions, el bombo i la caixa i les seues pulsions, / vinc seguint a Gramsci, que la història no és més que una guerra per l'hegemonia de les posicions / i en el meu camp de batalla jo tinc les cançons / Vull ser l'altaveu que rebente la norma i el llibres d'estil / Vull ser allò que no es veu, la mare que trau endavant als seus fills / Vull ser l'altaveu del xiquet que somia en un món ple d’amics / Vull ser Malcom X, tinc la paraula, tremolen els rics

Altres temes representatius d'aquest tipus podrien ser: "Escenes quotidines” i “Corbelles” de Zoo, "Cases de cartó” de Sant Gatxo, "Senyor pirotècnic" i “Tres de Pego" de La Gossa Sorda i “Batega la ciutat” d’Aspencat. En termes d’evolució de la cançó valenciana, aquest to solemne enllaçaria amb Al Tall, que dedica el primer disc, el 1979, a explicar la batalla definitiva -la d'Almansa- que va signifcar la fi de l'autogovern valencià el 1707. Pel que fa a cantautors, tindríem Raimon (amb les seues emblemàtiques cançons "Al vent" i “Diguem no") i, en una generació de grups posteriors, Obrint Pas.

Entremig d’aquests dos pols, la sàtira i l'himne, tindríem un conjunt ben ampli de grups i composicions musicals, que, sense el recurs a temàtiques explícitament polítiques, tenen l'expressió en valencià com a element fonamental de l’acció política. Ben explicat per ells mateixos, és una manera de "normalitzar" l'ús de la llengua pròpia, traure-la de l'àmbit privat, visibilitzar-la, buscant l'autoafirmació i tractant temàtiques molt diverses relacionades amb la quotidianitat o amb l'amor (estigmatitzat per la seua omnipresència en la música més comercial). Els grups més representatius d'aquest tipus de composicions en aquesta escena serien Arthur Caravan, Smoking Souls, Verdcel. Evolutivament, podria connectar amb les carreres d’artistes com Julio Bustamente, Remigi Palmero o Rafa Xambó.

És en aquest tercer grup de composicions on col-loquem altres formes d’expressió identitària i reivindicativa que, sense abandonar la "normalització" de la llengua, conjuguen aquesta naturalització del valencià en l'autoafirmació d'altres formes i àmbits invisibilitzats socialment i cultural que tenen a veure amb l'orientació sexual, el feminisme, el món rural i l’ecologia.

Si bé aquesta escena està molt masculinitzada -cosa molt habitual en el món del rock- apareixen dones en 29 unitats de la nostra base de dades, un $16 \%$, en les formacions dels grups (en molts casos com a cantants solistes) i grups formats exclusivament per dones. Trobem la presència femenina en aquesta escena en Pupil.les, La Tia Figa, el duo Júlia, ESIR, Barbaritats, Afrodita A, Sis Veus per al Poeta, Tito Pontet. Es pot dir que la perspectiva de gènere té una importància clau en aquests grups, i el feminisme és present en les seues lletres. En general, hi ha referències a la lluita feminista en els continguts d'aquesta escena (també de bandes masculines com en els temes "Dona d'aigua" i "El dia que tot rebente" de La Gossa Sorda, o els "Foc i vent" i "Hui la Liem" d’Auxili, també Andreu Valor en "No sé odiar, però vull" i "Crida" i "Batega la ciutat" d'Aspencat), de la mateixa manera que no s'observa, a grans trets, masclisme en les lletres. En paral.lel, en el circuit de festivals que ajuden a impulsar aquesta escena són habituals els "punts violeta" disposats per denunciar situacions d'assetjament sexual i de fòbia a la lliure orientació i identitat sexual. Pel que fa a les identitats i reivindicacions sexuals podem trobar King Kong Boy i el seu tema "Plena de vida", que tracta la transsexualitat, o en Pau Alabajos, que en "Sóller" narra una relació lèsbica, i "Lamor és cec" d’Arthur Caravan. Després d’afegir aquest tercer grup obtenim un quadre multicolor, en el qual es mostren entrecreuats tots aquests espais socials de dominació i en què es posen en qüestió les bases ideològiques de les exclusions, tot i que la identitat territorial hi tinga un paper preponderant.

Tornant als dos pols que estructuren aquesta identificació territorial (himne i xirigota), com a instruments d’agitació política, tots dos transmeten la idea de qüestionament del poder. Aparentment complementaris, utilitzen camins molt diferents. Si l'aspecte solemne i combatiu de l'himne projecta la idea d'un poder alternatiu -subverteix l'ordre establert per a orientar el canvi-, l'humor satíric transgredeix i, malgrat l'aparença inofensiva del riure i la festa, presenta un potencial polític més gran, pel fet que aquestes expressions es converteixen en alliberadores, negant els convencionalismes, neutralitzant la por i, al mateix temps, aportant un impuls de canvi i renovació. Recollim aquí la idea que el carnaval és l'expressió més genuïna del poble, i la seua sàtira va dirigida al que és constant, immortal i complet; i a tots, incloent-hi els mateixos participants del carnaval (Bajtin, 1998). És un aspecte autoparòdic molt present en la música que analitzem i connecta amb la importància que té la festa en la cultura valenciana.

L'autoparòdia s'observa en un bon nombre de composicions musicals analitzades. De "consum intern", superant l'estigmatització i l'estereotip que podria venir de fora -que seria ofensiu-, l'autoparòdia es reflecteix en l'assimilació del 
turista com a recurs econòmic, en l'exageració de l'ambient popular rural enfront de l'urbà, en les formes locals de parlar valencià o en la diversitat interna dels Països Catalans. Per a il-lustrar-ho amb exemples, Bacora, en el seu "Go home", denuncia la turistificació i els efectes que té sobre la identitat local i en "Poble apitxat", reivindica els ecolectes d'un idioma comú; i l'hilarant "Un CIE per als valencians" d'Ix! critica la suposada superioritat civicocultural de Catalunya enfront de la resta de territoris dels Països Catalans, proposant, en clau d'humor, la seua paradoxal expulsió d’aquesta unió cultural amb el passatge "fora Catalunya dels Països Catalans". Assumint els processos de descodificació, que estan determinats pels contextos socioculturals de recepció, en general, l'humor en la música permet percebre les jerarquies culturals, com indica Hawkings: "For one thing, sensing humour in music is an imaginative activity, and this is based on the role of identification and the manner by which we engage in styles, trends, idioms and, most importantly, cultural hierarchies" (Hawkings, 2007: 184)

Aquesta música, per tant, i com a forma universal d'expressió del poble, està acompanyada de l'humor carnavalesc per dotar de força els seus missatges. En els esdeveniments multitudinaris, l'humor i la festa tenen una dimensió política que convé assenyalar. Des d’un punt de vista sociològic, la festa és una interrupció de la rutina. Amb el carnestoltes -la màxima expressió de l’autogestió de la festa- es relaxen les normes, i la disfressa fa possible permutar els rols, també les jerarquies. Durant uns quants dies és el poble qui governa (en alguns llocs, l'alcalde lliura la vara de comandament al rei del carnaval o similar). La festa, com el riure, a més d'alliberament individual i col-lectiu, genera un clima de canvi i renovació. Sense encadenament en el temps (la seua principal característica és la discontinuïtat), proporciona una forma d'expressió política (en part per la recerca d’espectacularització mediàtica, però també com a atractiu per a la mobilització) que ja és àmpliament utilitzada en les protestes polítiques que travessen el planeta i en totes les lluites dels diferents moviments socials.

Aquest és un aspecte rellevant perquè connecta amb la configuració dels nous moviments socials després de la crisi dels moviments socials tradicionals (obrers, jerarquitzats i instrumentalitzats pels partits polítics). Després de les experiències mobilitzadores dels anys seixanta i setanta de segle passat (que s'afegeixen a les reivindicacions laborals, les mediambientals, feministes i pacifistes), els nous moviments socials es renoven amb les reivindicacions més enllà de les fronteres estatals -en interconnexió mundial gràcies a l'ús intensiu de les xarxes tecnològiques- i incorporant la idea de convergència de lluites que, en aparença, és paradoxal. Les fragmentacions identitàries i de les reivindicacions concretes contrasten amb l'esforç de connexió en xarxa i amb el seu caràcter intergeneracional i, fins i tot, interclassista. En aquesta renovació en la mobilització, dins d’aquest nou cicle de protesta global que tractàvem més amunt, tenen protagonisme els "novíssims moviments socials", els quals abandonen totalment les estructures jerarquitzades i la conquesta del poder polític en un esforç per aconseguir una globalització alternativa. Un apel-latiu -novíssim- que Juris, Pereira i Feixa (2012) incorporen per a descriure els ambients festius, multiacolorits i tecnologitzats de les protestes del moviment altermundialista, en què la música sempre està present.

\section{Conclusions. Territori i resistència en els moviments socials}

En aquest treball hem intentant descriure i explicar el procés de desenvolupament d'una escena musical mostrant com incideixen els factors estructurals (culturals, històrics, socials i geogràfics) en la formació d'una escena de caràcter eminentment polític i connectada amb els moviments socials.

A partir d'aquesta contextualització, hem caracteritzat aquesta escena en relació amb els estils i les fonts d'inspiració. Tot i la gran heterogeneïtat de gèneres derivats del rock, destaquem els elements polítics com a principal denominador comú del conjunt de bandes que formen aquesta escena. Considerem que l'autenticitat, concepte polèmic i multisèmic de l'activitat artística, que conjuga les nocions d’originalitat, credibilitat i independència en la creació i en la interpretació musical, es forma en aquesta escena a partir de múltiples essencialismes relacionats amb la identitat (generacional, territorial), l'ús de la llengua pròpia, l’autoproducció, la música en directe i la resistència política. D’altra banda, aquest àmbit és un exemple de la manera en què la música pot orientar la lluita política a partir de la vinculació dels músics i la seua música amb els moviments socials, al mateix temps que dóna forma a l'acció política. A partir de l’anàlisi dels estils literaris de les cançons, observem tres grups de composicions -estructurades a partir de dos pols (el solemne i el satíric)- que indiquen maneres d’expressió que connecten amb les formes actuals d'acció política dels moviments socials. Moviments socials que intenten actuar a escala global, però que estan fragmentats des del punt de vista identitari. El fet que la música acompanye un gran nombre de protestes multitudinàries que se celebren internacionalment ens porta a observar un tipus paròdic molt característic - arrelat en la societat i la cultura valencianes- que exemplifica una forma d’acció política descentralitzada, espontània, transversal i horitzontal. 
Des d'aquesta perspectiva, les conclusions de l'estudi d'aquesta escena musical intenten contribuir al coneixement de les pràctiques culturals que estructuren la participació política dels moviments socials en un món cada vegada més globalitzat. Unes pràctiques musicals que podrien ser caracteritzades com a "glocals", enteses com l'expressió local d’allò global i que mostren les contradiccions entre l'homogeneïtat i heterogeneïtat culturals productes de la globalització, al mateix temps que contenen un sentit global del lloc (Massey, 2004)

És per això que considerem que les reivindicacions identitàries i socials d’aquesta escena musical són més formes d’autoafirmació i resistència espontànies que un projecte polític concret. En els moviments socials contemporanis hi ha més lluita en els camps culturals que en el camp de la política institucional, i els dubtes que mostren cap a l'Estat, com a instrument d'alliberament, són evidents. Certament, en l'estadi actual del procés globalitzador, l'estat nació perd pes en relació amb altres actors transnacionals i supranacionals, com són els organismes internacionals i els personificats "mercats", capaços d’imposar polítiques d’austeritat, fins i tot amb l'ús de la força militar. S’associa, per tant, aquesta dimensió política de la cultura amb la idea de l’acumulació lineal de pràctiques quotidianes autogestionades d'oposició que proposa, des del marxisme, Holloway (2002) en el seu Change the world without taking power. Lautor posa en qüestió les jerarquies establides durant molt de temps en l'evolució dels moviments socials i les diferents formes de lluita social. Jerarquies que col-loquen en un rang superior les dels partits. Organitzacions que contribueixen, segons l'autor, a disciplinar la "lluita de classes":

At the top of the hierarchy we learn to place that part of our activity that contributes to "building the revolution", at the bottom come frivolous personal things like affective relations, sensuality, playing, laughing, loving. Class struggle becomes puritanical: frivolity must be suppressed because it does not contribute to the goal. The hierarchisation of struggle is a hierarchisation of our lives and thus a hierarchisation of ourselves (Holloway, 2002, p. 21).

Si els moviments socials han après que la lluita és transversal, intersectorial, és perquè la política s'ha de tractar en termes biopolítics per fer notar les múltiples exclusions que travessen l'espai social. Tot fenomen cultural és el resultat de molts poders en pugna, que intenten posicionar-se en els seus idearis i representació (Hall, 2011), en què l'Estat és un més, però no el poder del qual emana la resta. Al llarg del planeta (des de la inspiració de el moviment de Chiapas d'un líder sense rostre que no arriba ni al grau de comandant, Marcos) es construeixen, cada vegada amb més sincronia en les seues accions polítiques, els territoris de resistència, en els quals, en termes geogràfics, es posa en valor el lloc, enfront de l'espai. Així, en aquesta escena descrita en aquest text, veiem una expressió particular d'un conjunt de pràctiques culturals que travessen les fronteres. La cultura desenvolupada en múltiples espais es revalora, el component polític s'estén a qualsevol forma d'exclusió i invisibilització, i és possible conèixer i entendre totes aquestes formes perquè les diferents composicions i estils musicals mostren les contradiccions internes d'aquest moviment altermundialista. D’una banda, aparenten ser lluites identitàries fragmentades, sense líders ni organitzacions molt articulades i jerarquitzades; d’altra banda, es troben múltiples camps (polítics i artístics) on es representen aquestes diferències i la voluntat de ferles convergir. També a través del llenguatge universal de la música i de la dansa, com expressava Emma Goldman: "If I cant't dance to it, it's not my revolution."

Així, en aquest treball hem observat com el marc geogràfic s’impregna de significat a través de la música. Els llocs s'omplin d'identitat i mostren la vida quotidiana, els paisatges, les vivències dels subjectes que, mitjançant les narratives de la memòria de l'espai social, donen contingut i interpretació del món al mateix temps que hi actuen. Aquesta escena musical és un exemple de la manera en què es practica la lluita en el camp cultural d'un territori.

Davant l'espai de la globalització i el capital, aquesta escena analitzada proposa el lloc o, més ben dit, els llocs que componen Diània. En la seua vessant musical identitària, és un exemple de pràctiques que s'oposen a la política cultural valenciana dels últims anys, caracteritzada pels projectes caríssims tacats per la corrupció que buscaven la connexió internacional a través de les ciutats, amb megaprojectes urbanístics i arquitectònics, amb esdeveniments esportius (circuit de Fórmula 1 a València), religiosos (rebuda del papa Ratziger), i també musicals (Julio Iglesias com a ambaixador mundial de la Comunitat Valenciana). Des d'un punt de vista geogràfic, enfront de la perspectiva anònima de l'espai, que intenta observar a vista d’ocell la ubicació dels recursos humans i materials per a transformar-los -i el seu correlat d'homogeneïtzació i mercantilització de la cultura-, es contraposa la perspectiva més reduïda del lloc (des d’on es pot parlar del món amb les narratives de l'etnicitat, Hall, 1997), on cada individu ompli aquest espai subjectivament en interacció amb altres individus i la natura, precisament en un moment d’amenaça tant de la societat com de la natura (Piqueras, 2017).

Quan aquest espai es matisa pel lloc i s'associa a un programa polític, apareix el "territori" i, amb aquest, les expressions sociopolítiques de l’activitat artística: pertinença, apropiació, ús, arrelament, vincle comú sentimental dels habitants, i resistència. Un territori que és travessat per totes les lluites de posicionament dins d'una societat global i en el qual diferents col-lectius, més o menys estructurats, intenten convertir-lo en territori de resistència al procés d'homogeneïtzació cultural i domini (Harvey, 2000; Escobar, 2001; Castells, 2003). Com a tendència expressa una ressignificació de l’àmbit local, en el sentit de reconstrucció i reafirmació de l'espai que és comunitari i socioterritorial. 


\section{Referències bibliogràfiques}

Alaminos, A. i Penalva, C. (2013). “España: de los impactos de la crisis a las movilizaciones de protesta”. Ecuador Debate, 89, 93-117.

Alaminos Fernández, A. (2014). "La música como lenguaje de las emociones. Un análisis empírico de su capacidad performativa”. OBETS-Revista de Ciencias Sociales, 9 (1), 15-42. https://doi.org/10.14198/OBETS2014.9.1.01

Albert, M. i Hernàndez i Martí, G.M. (2011). "La identidad en lucha. Iniciativas civiles culturales ante el conflicto identitario valenciano”. Papeles del CEIC, 2011/1 (66), http://www.identidadcolectiva.es/pdf/66.pdf.

Bajtin, M. (1998). La cultura popular en la Edad Media y en el Renacimiento: el contexto de François Rabelais. Madrid: Alianza.

Biddle, I. i Knights, V. (Eds.) (2007). Music, national identity and the politics of location: Between the global and the local. London: Ashgate.

Casado, J. M. i Salom, J. (2007). "Movilidad cotidiana y mercados locales de trabajo en la Comunidad Valenciana, 19912001”. Boletín de la Asociación de Geógrafos Españoles, 44, 5-28.

Castells, M. (2003). La era de la información. Vol.2: El poder de la identidad. Madrid: Alianza.

Català-Oltra, L. (2012). Fonaments de la identitat territorial. Alacant. Universitat d'Alacant (tesi doctoral).

Català-Oltra, L. (2016). Comarques Centrals. La via per a la vertebració territorial del País Valencià. València: Institut Ignasi Villalonga.

Català-Oltra, L. i Penalva, C. (2018). Lús de les llengües en la comunicació telemàtica de l'administració local valenciana. València: Generalitat Valenciana.

Cervera, J. I. (2011). Comarques Centrals Valencianes. Un nou marc cap al desenvolupament territorial sostenible. València: Universitat de València.

Escobar, A. (2001). "Culture sits in places: reflections on globalism and subaltern strategies of localization". Political Geography, 20, 139-174. https://doi.org/10.1016/S0962-6298(00)00064-0

Espinosa, P. i López, E. (1993). Hertzainak. La confesión radical. Vitoria: Alanai.

Eyerman, R. i Jamison, A. (1998). Music and Social Movements: Mobilizing Traditions in the Twentieth Century. New York: Cambridge University Press. https://doi.org/10.1017/CBO9780511628139

Frith, S. (2003). “Música e identidad”. A S. Hall i P. du Gai (comp.), Cuestiones de identidad cultural. Madrid: Amorrortu, 181-213.

Frechina, J. V. (2012). La cançó en valencià. Dels repertoris tradicionals als gèneres moderns. València: Acadèmia Valenciana de la Llengua.

FSMCV (2015). Censo de agrupaciones artísticas de las sociedades musicales de la comunidad valenciana. Valencia: Federación de Sociedades Musicales de la Comunidad Valenciana. http://www.ateneulavila.com/contingut/docs/ FSMCV_Censo\%20agrup_artst.pdf.

Fuster, J. (1962). Nosaltres els valencians. Barcelona: Edicions 62.

Jaspers, J. M. (2012). “¿De la estructura a la acción? La teoría de los movimientos sociales

después de los grandes paradigmas". Sociológica, 27 (75), 7-48.

Juris, J.S., Pereira, I., Feixa, C. (2012). “La globalización alternativa y los 'novísimos' movimientos sociales”. Revista del Centro de Investigación. Universidad La Salle, 10 (37), 23- 39.

Hall, S. (1997). “The Local and the Global: Globalization and Ethnicity”. En A. D. King (ed.), Culture, Globalization, and the 
World-System: Contemporary Conditions for the Representation of Identity. Minneapolis: NED-New Edition/University of Minnesota Press, 19-40. https://doi.org/10.1007/978-1-349-11902-8 2

Hall, S. (2011). La cultura y el poder: conversaciones sobre los cultural studies. Buenos Aires: Amorrortu.

Harvey, D. (2000). Espacios de esperanza. Madrid: Akal.

Hawkins, S. (2007). “Those Norwegians: Deconstructing the Nation-State in Europe through Fixity and Indifference in Norwegian Club Music”. En I. Biddle i V. Knights (eds.), Music, National Identity, and the Politics of Location: Between the Global and the Local. London: Ashgate, 179-190. https://doi.org/10.4324/9781315596914-10

Holloway, J. (2002). Cambiar el mundo sin tomar el poder. El significado de la revolución hoy. Buenos Aires: Herramienta Ediciones/Universidad Autónoma de Puebla.

Llopis, R., i Vidal, M. (2006). "Localismo o redes territoriales en el desarrollo local de la Comunidad Valenciana”. Investigaciones regionales: Journal of Regional Research, 9, 139-144.

Massey, D. (2004). "Lugar, identidad y geografías de la responsabilidad en un mundo en proceso de globalización”. Treballs de la Societat Catalana de Geografia, 57, 77-84.

Membrado, J. C. (2013). "La división territorial valenciana: antecedentes, problemas y política de la Generalitat". Investigaciones Geográficas, 59, 5-24. https://doi.org/10.14198/INGEO2013.59.01

Mora, K. i Viñuela, E. (eds.) (2013). Rock around Spain. Historia, industria, escenas y medios de comunicación. Lleida: Edicions de la Universitat de Lleida.

Montoya, B. (2012). La transmissió familiar del valencià. València: Generalitat Valenciana.

Moso, R. (2013): "El rock radikal vasco. Ruido y rabia en la zona especial norte”. A K. Mora i E. Viñuela, Rock around Spain. Historia, industria, escenas y medios de comunicación. Lleida; Universitat de Lleida, 111-120.

Novell, N. (1997). "Introducció". A R. Ninyoles, Informe sociològic de les Comarques Centrals Valencianes. Gandia: CEIC Alfons el Vell, 7-47.

Novell, N. (2015). “Les Comarques Centrals Valencianes (la Governació de les Muntanyes): un projecte carregat de sentit”. a paisvalenciaseglexxi.com, 19 i 20 de juliol.

Planas, X. (2012). “Joan Fuster i la nova cançó”. En J. Iborra, J. Baptista et. al. Joan Fuster i la música. Valencia: Universitat de València, 23-34.

Pedelty, M. i Weglarz, K. (eds.) (2013). Political Rock. Farnham: Ashgate.

Pellicer, J. (2002). Meravelles de Diània: camins, paratges i paisatges de les comarques centrals valencianes. Picanya: Edicions del Bullent.

Piqueras, A. (2017). La tragedia de nuestro tiempo: la destrucción de la sociedad y la naturaleza por el capital. Madrid: Anthropos.

Raffini, L., Penalva, C. i Alaminos, A. (2015). "Antiausteridad y protesta en el contexto de la crisis económica y política en España e Italia”. Società Mutamento Politica, 11 (6), 23-50.

Salom, J. i Albertos, J.M. (2014). “Delimitación y caracterización de los nuevos espacios urbanos valencianos”. Boletín de la Asociación de Geógrafos Españoles, 64, 127-149.

Sanchis Deusa, M. C. (1976). "El área de influencia de Xàtiva”. Cuadernos de Geografía, 19, 41-66.

Val, F. del i Fouce, H. (2016). "De la apatía a la indignación. Narrativas del rock independiente español en época de crisis". Methaodos-revista de ciencias sociales, 4 (1), 58-72. http://dx.doi.org/10.17502/m.rcs.v4i1.105.

Ybarra, J.A. (2011). Un territori per al desenvolupament: les Comarques Centrals Valencianes davant el seu futur. València: Universitat de València. 